\title{
NEW EDITOR-IN-ChIEF ANNOUNCEMENT
}

On behalf of the search committee for Editor-in-Chief of the Panamerican Journal of Trauma, Critical Care \& Emergency Surgery (PAJTCCES), I am pleased to announce that the new Editor-in-Chief (EIC) will be Sandro Rizoli. He succeeded Dr Rao Ivatury on August 1, 2019. Dr Rizoli was selected from an international group of candidates.

I would like to thank all the members of the search committee including Dr Carlos Morales, Dr Dario Birolini, Dr Napoleon Mendez, Dr Felipe Vega, Dr Antonio Marttos, Dr Thomas Scalea, Dr Rao Ivatury, Dr Paula Ferrada, Dr Esteban Foianini, Dr Michel Aboutanos, and Dr Carlos Ordonez, for their commitment during the recruitment and selection process of the new EIC. There were several qualified applicants for the position making the decision difficult for the committee members.

Second, I want to thank Dr Ivatury, who revamped the journal, built on the work of prior eminent editors,

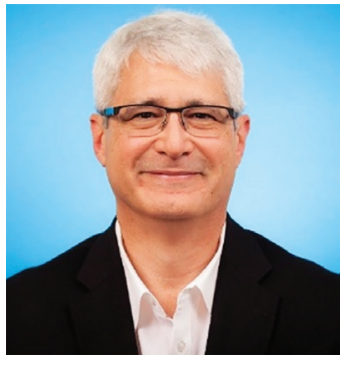
and established a tradition of quality research during the last eight years of service. We all owe him a debt of thanks. Dr. Ivatury will continue to be involved with the journal in a new role as Editor-in-Chief Emeritus.

The Panamerican Trauma Society (PTS) has high expectations for the journal. Having the journal indexed soon is the most urgent. To reach this goal, the Society is asking the new EIC to make the needed modifications, including the formation of a new editorial board that will inject the energy needed and will open the opportunity for talented PTS members to actively participate.

Our goal is to expand the relevance of the journal worldwide creating a desired place to publish the best scientific work in trauma, critical care, and emergency surgery. The journal must continue to represent all the PTS must strive, in particular, to be a vehicle for publications from Latin America.

Please join us in wishing Sandro all the best in his new role. We are fortunate to have such an experienced individual in the EIC position, who will continue to develop the journal into a higher level in the world.

Sincerely,

Thomas M Scalea

Executive Director

Panamerican Trauma Society 